\title{
The Comparative Analysis of Conditions \\ of Extraction Anthocyanins \\ of Fruits Aronia Melanocarpa Siberian Region
}

\author{
Svetlana A. Polina ${ }^{a}$, \\ Natalia E. Khmarskaya ${ }^{a}$ and Alexander A. Efremov ${ }^{\mathrm{a}, \mathrm{b} *}$ \\ ${ }^{a}$ Siberian Federal University \\ 79 Svobodny, Krasnoyarsk, 660041, Russia \\ ${ }^{b}$ Krasnoyarsk Scientific Center of the $R A S$ \\ 50 Akademgorodok, Krasnoyarsk, 660036, Russia
}

Received 22.04.2015, received in revised form 03.05.2015, accepted 23.05.2015

The article contains information about determination composition of anthocyanins of frozen fetuses of black chokeberry (Aronia melanocarpa) which grow in Yenisei and Shushensky districts of the Krasnoyarsk krai by HPLC with UV detection. Describes the conditions for optimal extraction of anthocyanin with water and different concentrations ethyl hydroxide. Comparative analysis of the qualitative composition and quantitative content of anthocyanin.

Keywords: Aronia melanocarpa, cyanidin-3-galactoside, cyanidin-3-glucoside, cyanidin-3arabinoside, cyanidin-3-xyloside, anthocyanins, extract, HPLC.

(C) Siberian Federal University. All rights reserved

* Corresponding author E-mail address: AEfremov@sfu-kras.ru 


\title{
Сравнительный анализ условий
}

\section{экстракционного извлечения антоцианов Aronia Melanocarpa Сибирского региона}

\author{
С.А. Полина ${ }^{a}$, Н.Е. Хмарская ${ }^{a}$, А.А. Ефремов ${ }^{a, 0}$ \\ ${ }^{a}$ Сибирский федеральный университет \\ Россия, 660041, Красноярск, пр. Свободный, 79 \\ ${ }^{6}$ Красноярский научный иентр СО РАН \\ Россия, 660036, Красноярск, ул. Академгородок, 50
}

\begin{abstract}
В статье приведены данные о количественном содержании индивидуальных антоцианов в мороженых плодах Aronia melanocarpa, собранных на территории Енисейского и Шушенского районов Красноярского края. Отмечены условия для оптимального извлечения анточианов водой и этиловым спиртом разной концентрации. Проведено сравнение качественного состава и количественного содержания антоцианов.
\end{abstract}

Ключевые слова: Aronia melanocarpa, циианидин-3-галактозид, ичианидин-3-глюкозид, циианидин3-арабинозид, цианидин-3-ксилозид, антоцианы, экстракт, ВЭЖХ.

\section{Введение}

Арония черноплодная - сильно ветвящийся кустарник семейства розоцветных, до 3 м высотой. Особенностью аронии является большая побеговосстановительная способность. Плод довольно сочная, кисловато-сладкая ягода с вяжущим терпковатым привкусом. Плоды шаровидные, реже сдавленно-округлые, черные, блестящие, с сизым налетом, созревают в конце августа - начале сентября. Родина растения - Северная Америка. Арония черноплодная широко культивируется в Российской Федерации, в особенности в Ленинградской области, Алтайском крае, на Урале, Сахалине и в других регионах. В плодах аронии обнаружены сахара (до 10 \%), яблочная и другие органические кислоты (до $1,3 \%$ ), пектиды (до 0,75 \%) и дубильные вещества (до 0,6 \%). Суммарное содержание антоциановых пигментов в зрелых плодах доходит до $6,4 \%[1,2]$.

Антоцианы являются антиоксидантами, широко используются в пищевой, медицинской, фармакологической, косметической промышленности [3, 4].

В Красноярском крае была изучена рябина черноплодная, произрастающая в районе г. Зеленогорска (Рыбинский район), исследована сохранность БАВ в зависимости от условий дробления и влияние процесса измельчения ягод на выход БАВ при экстрагировании 60\%-ным спиртом [5]. В работе [6] предложили оптимальные условия экстракции натуральных антоциановых красителей (в качестве экстрагента выбран 96\%-ный этиловый спирт) и метод ВЭЖХ для контроля качественного и количественного состава антоциановых пигментов. Также были установлены оптимальные условия экстракции антоцианов из высушенных и свежесобранных плодов рябины черноплодной [7]. Однако результаты, представленные в литературе, противо-

$$
-223-
$$


речивы, в работах российских учёных отсутствуют данные о суммарном содержании и содержании индивидуальных антоцианов. В исследованиях зарубежных авторов эти данные представлены в [8-12], но в указанных работах исследована рябина черноплодная, произрастающая за границей Российской Федерации.

С учетом всего вышесказанного представляет интерес исследовать антоциановый состав рябины черноплодной, произрастающей в Красноярском крае, подобрать условия экстрагирования из сырья.

\section{Экспериментальная часть и обсуждение результатов}

Исследуемые в данной работе ягоды рябины черноплодной были собраны на территории Енисейского и Шушенского районов Красноярского края. Плоды были заморожены. Срок годности для замороженных ягод составляет 6 месяцев [13]. В течение этого времени ягоды практически полностью сохраняют вкусовые качества и питательные вещества. Таким образом, использование в производстве замороженных ягод рябины черноплодной позволит устранить сезонность их переработки, обусловленную коротким периодом массового сбора, и обеспечить ценным сырьем и витаминами в осеннее-зимний период.

При использовании водно-спиртовых растворов для экстрагирования из сырья могут извлекаться частично как водорастворимые, так и спирторастворимые фракции. В химическом составе плодово-ягодного сырья преимущественно преобладают водорастворимые фракции (фенольные вещества, в том числе лейкоантоцианы и рутин, аскорбиновая кислота, сахара) [14].

Известно, что потери антоцианов при сушке составляют 50-90 \%. В связи с этим для анализа были использованы замороженные плоды рябины черноплодной [15].

Также на концентрацию антоцианов влияет срок хранения сырья и особенно сильно сорт, место произрастания и степень вызревания ягод. Увеличить концентрацию антоцианов в экстракте можно, уменьшая количество растворителя в соотношении растворитель : сырьё [16].

В ходе эксперимента было получено 50 спиртовых экстрактов ягод, 5 из них настаивались на 40\%-ном спирте, содержащем $1 \% \mathrm{HCl}$, при комнатной температуре в течение $15,30,45,60$, 90 мин при соотношении сырье:экстрагент 1:30, 45 экстрактов получали нагреванием на кипящей водяной бане в течение $15,30,45,60$ и 90 мин с соотношением сырье:экстрагент 1:30, 1:50 и 1:100. Для экстракции использовался 40-, 60- и 95\%-ный этиловый спирт с добавлением $1 \%$ $\mathrm{HCl}$. Нагреванием на плите в течение 15 мин было получено 10 водных экстрактов, 5 экстрактов с добавлением $1 \% \mathrm{HCl}$ и 5 - без нее.

Экстракты плодов рябины черноплодной по отдельности хроматографировали на жидкостном хроматографе Agilent 1200 при следующих условиях: колонка Luna 5u C18(2) 100A (250x4,6mm5 мкм); температура термостата $25{ }^{\circ} \mathrm{C}$; длина волны детектирования 543 нм; подвижная фаза: ацетонитрил; 0,01\%-ный раствор фосфорной кислоты в воде; режим элюирования градиентный (табл. 1). Сбор данных, обработку хроматограмм и спектров поглощения осуществляли с помощью программы AgilentChemStation. Идентификацию пиков проводили по литературным данным, сопоставляя времена удерживания на аналогичных колонках, и УФспектрам индивидуальных компонентов [8-12, 17, 18]. Отдельно фиксировали растворы стан- 
Таблица 1. Режим элюирования

\begin{tabular}{|c|c|}
\hline Время, мин & Содержание ацетонитрила, об. \% \\
\hline $0-10$ & 15 \\
\hline $10-20$ & $15-30$ \\
\hline $20-30$ & $30-15$ \\
\hline
\end{tabular}

дартного образца цианидин-3-глюкозида с разной концентрацией и строили градуировочный график. Сравнивали времена удерживания и УФ-спектры стандартного вещества и данного вещества, обнаруженного в экстрактах. Установлено, что нижняя граница определяемых содержаний цианидина-3-глюкозида 0,01 мкг/мл .

Далее на спектрофотометре SPEKOL 1300 снимали оптическую плотность экстрактов при длине волны 543 нм.

Результаты анализа представлены в табл. 2. Наибольшее суммарное извлечение антоцианов наблюдается при экстракции 40\%-ным спиртом с добавлением $1 \% \mathrm{HCl}$, гидромодуль 1:30 в течение 15 мин - 902,2 4,9 мг/100 г. По литературе суммарное извлечение антоцианов рябины черноплодной варьируется от 307 до 1480 мг/100 г в зависимости от региона произрастания и сорта [8-12]. Экстракция антоцианов зависит от продолжительности нагревания на кипящей водяной бане. Увеличение температуры ускоряет процесс экстрагирования, но это отрицательно сказывается на ценных веществах экстракта, происходит разрушения антоцианов - суммарное извлечение антоцианов уменьшается. Такие же выводы можно сделать, анализируя оптические плотности данных экстрактов (рис. 1). Интересно, что концентрации индивидуальных антоцианов при нагревании на кипящей водяной бане с течением времени изменяются по-разному степень извлечения индивидуальных антоцианов различна. Очевидно, что когда концентрация цианидина-3-галактозида увеличивается, концентрация неидентифицированного компонента

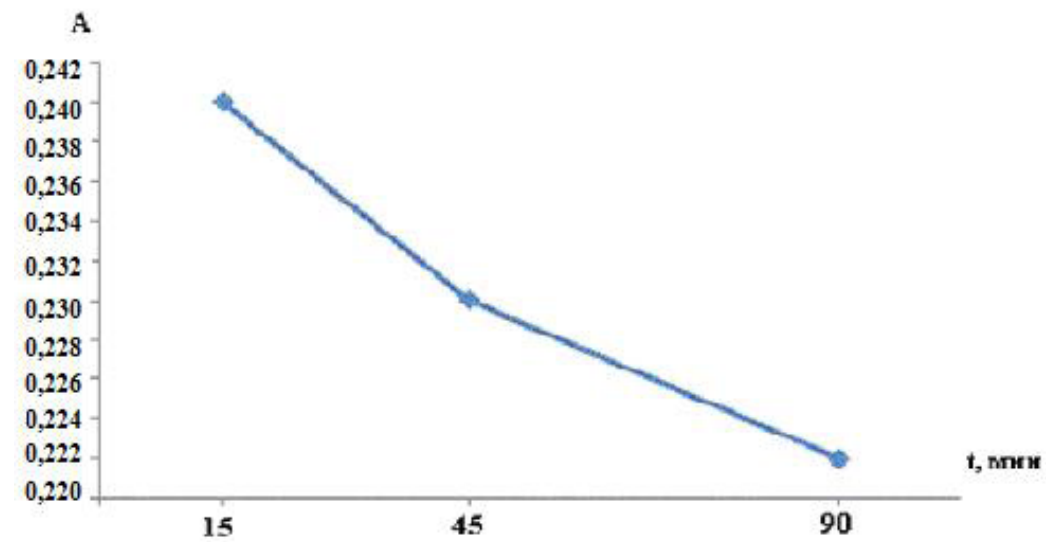

Рис. 1. Зависимости оптической плотности от времени экстракции в разбавленных 10 растворах, приготовленных из экстрактов черноплодной рябины (экстракция 40\%-ным спиртом с добавлением $1 \%$ $\mathrm{HCl}, \lambda=543$ нм) 


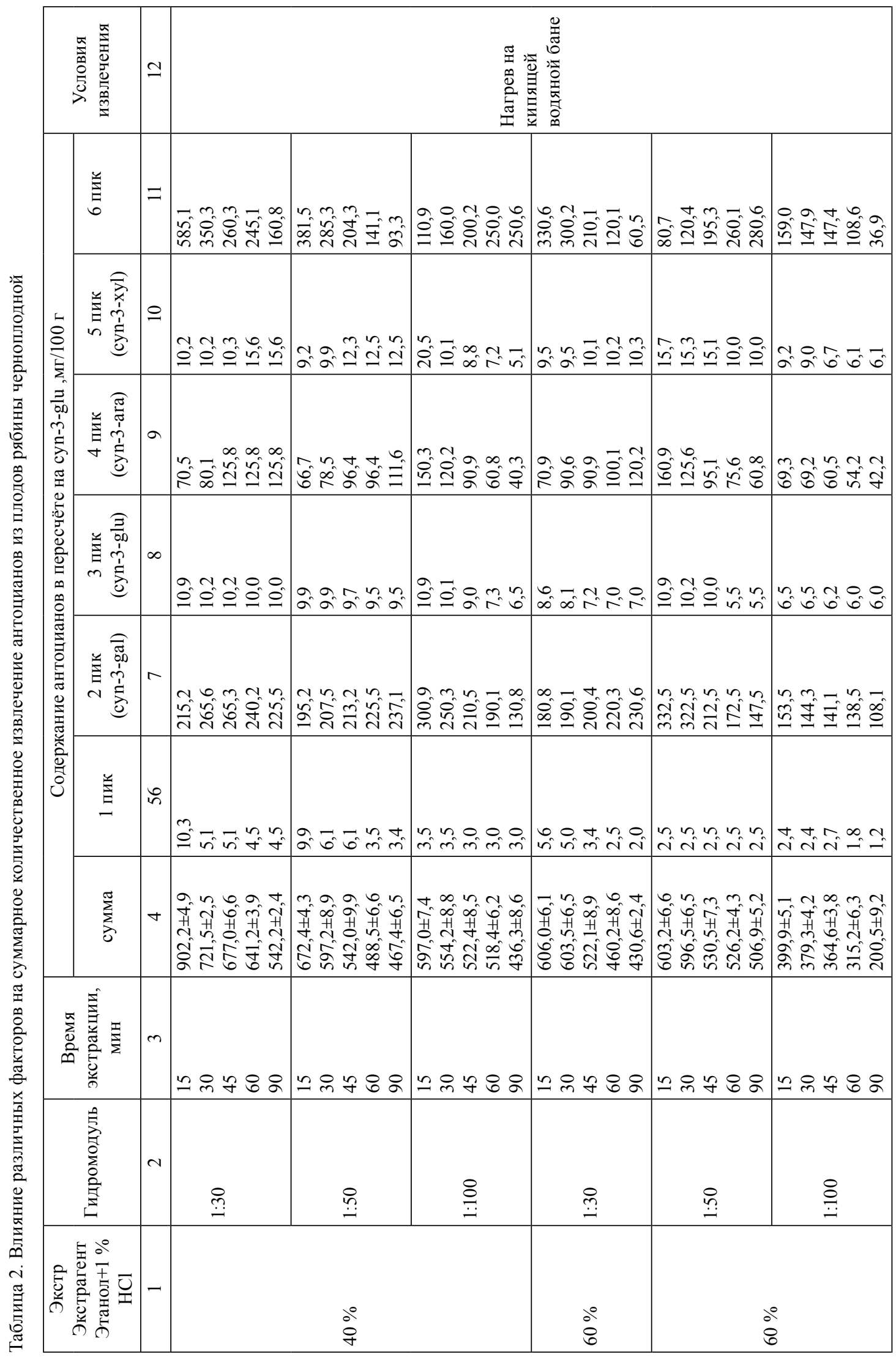




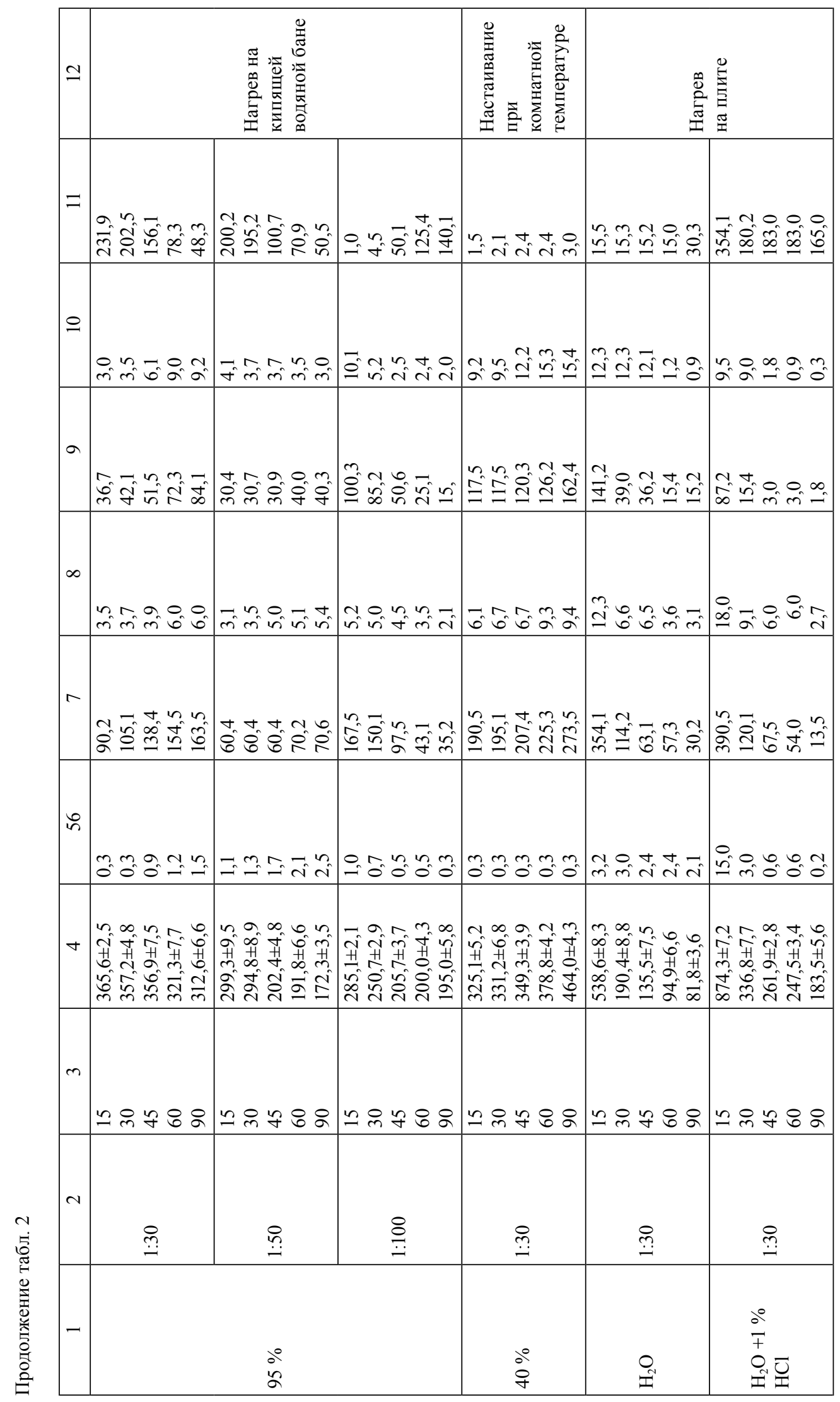


(номер пика 6) уменьшается, и наоборот. На рис. 2 и 3 представлены хроматограммы, которые наглядно демонстрируют разную степень извлечения индивидуальных антоцианов при разных условиях экстракции, например неидентифицированный компонент (номер пика 6) в первом случае по площади превышает все остальные, на второй же хроматограмме данный пик очень слабо выражен. Суммарное содержание антоцианов и концентрация индивидуальных антоцианов при настаивании увеличивается с течением времени. При проведении экстракции водой, нагреванием экстракта на плите наблюдается высокая степень извлечения, например

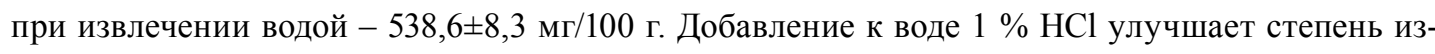
влечения почти в два раза.

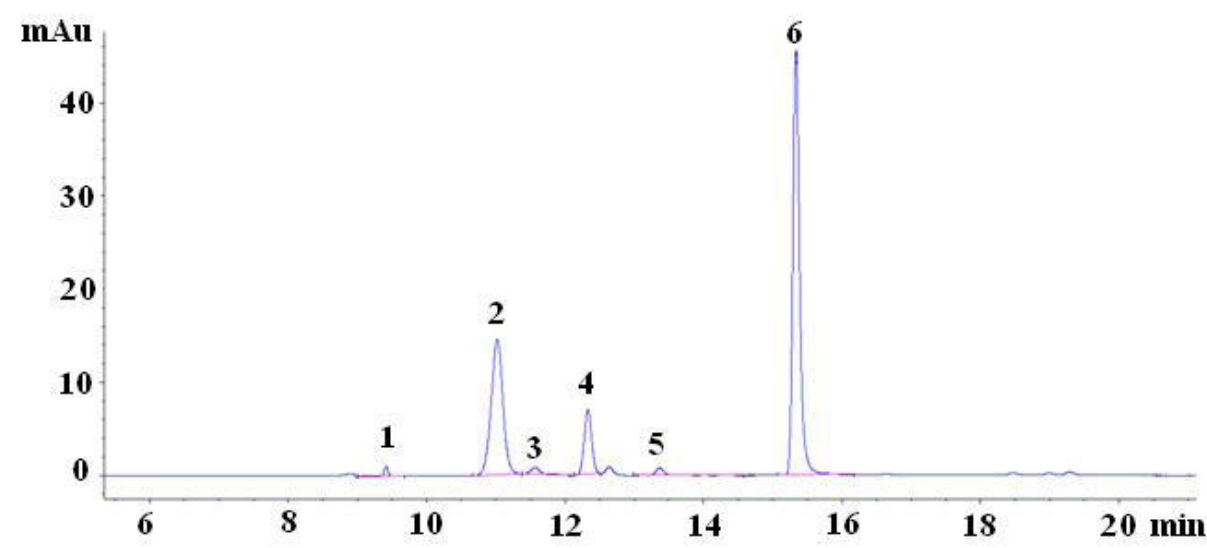

Рис. 2. Хроматограмма антоцианов плодов рябины черноплодной (экстракция 60\%-ным спиртом с добавлением $1 \% \mathrm{HCl}$, гидромодуль 1:30, 15 мин): 1 - не идентифицирован $(\operatorname{tr}=9,409$ мин); 2 - цианидин3 -галактозид ( $\operatorname{tr}=11,015$ мин); 3 - цианидин-3-глюкозид $(\operatorname{tr}=11,561$ мин); 4 - цианидин-3-арабинозид $(\operatorname{tr}=12,323$ мин); 5 - цианидин-3-ксилозид $(\operatorname{tr}=13,359$ мин); 6 - не идентифицирован $(\operatorname{tr}=15,329$ мин $)$

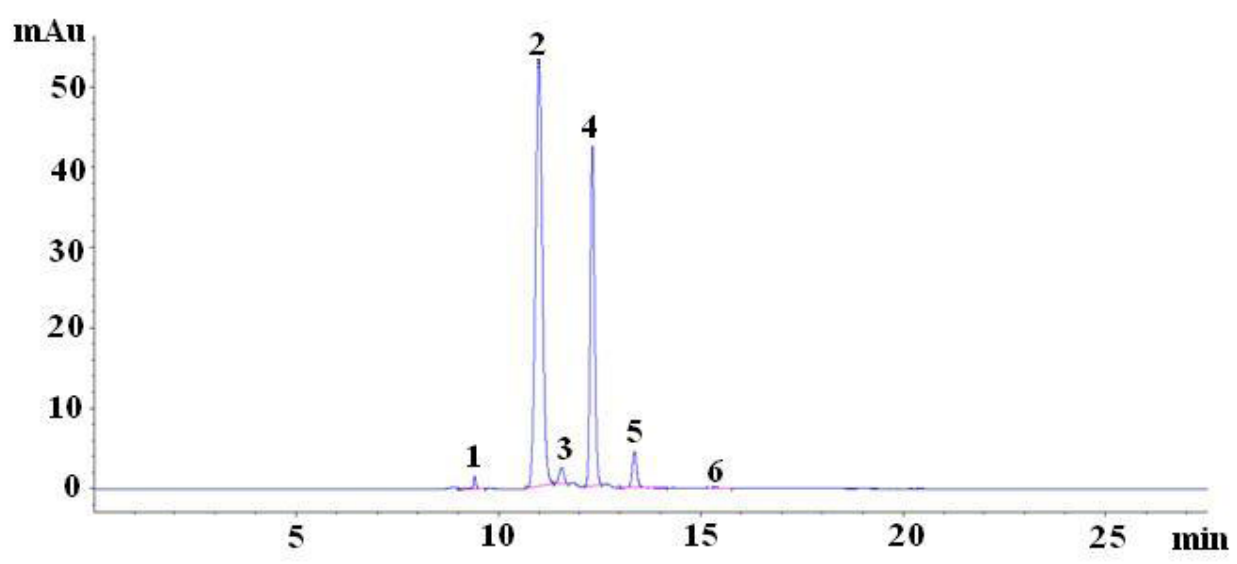

Рис. 3. Хроматограмма антоцианов экстракта плодов рябины черноплодной, полученного настаиванием при комнатной температуре в 40\%-ном спирте в течение 90 мин: 1 - не идентифицирован $(\operatorname{tr}=9,402$ мин); 2 - цианидин-3-галактозид ( $\operatorname{tr}=10,988$ мин); 3 - цианидин-3-глюкозид $(\operatorname{tr}=11,549$ мин); 4 - цианидин-3арабинозид $(\operatorname{tr}=12,309$ мин); 5 - цианидин-3-ксилозид $(\operatorname{tr}=13,350$ мин); 6 - не идентифицирован $(\operatorname{tr}=15,339$ мин) 


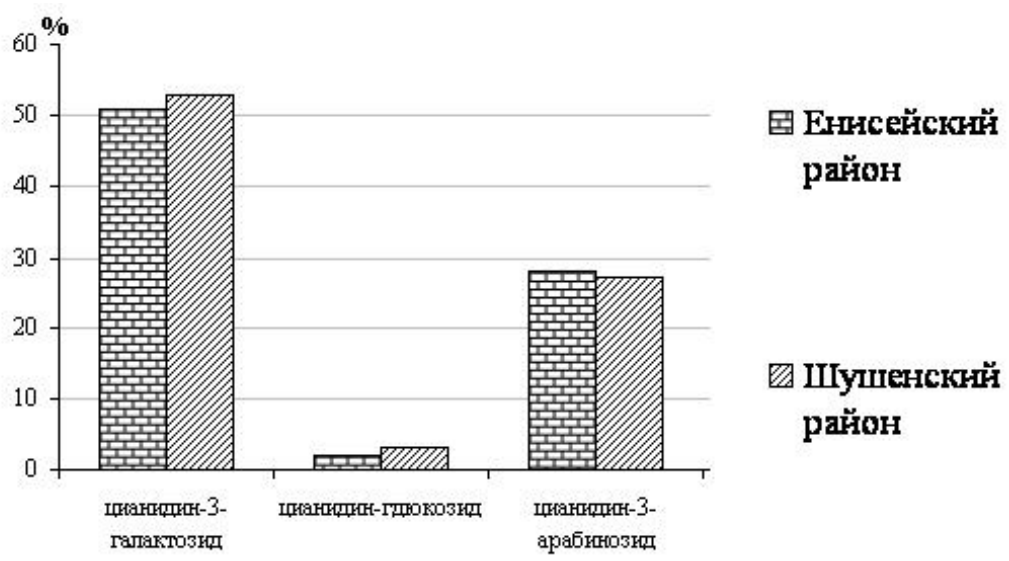

Рис. 4. Сравнение процентного содержания индивидуальных антоцианов от суммарного содержания ягод рябины черноплодной в двух районах Красноярского края

В экстрактах рябины черноплодной обнаружено шесть веществ с максимумами поглощения спектров, характерных для антоцианов (в УФ $281 \pm 2$ нм и в видимой области $543 \pm 2$ нм). Из них четыре удалось идентифицировать: 2-цианидин-3-галактозид, 3 - цианидин-3-глюкозид, 4 - цианидин-3-арабинозид, 5 - цианидин-3-ксилозид.

При сравнении экстрактов, приготовленных из рябины черноплодной, произрастающей в Енисейском и Шушенском районах Красноярского края, было установлено, что антоциановый состав данных ягод как качественно, так и количественно отличается незначительно (рис. 4).

\section{Выводы}

1. Установлены оптимальные условия для извлечения индивидуальных антоцианов из плодов рябины черноплодной Красноярского края (при проведении экстракции нагреванием на водяной бане 15 мин 40\%-ным спиртом с добавлением $1 \% \mathrm{HCl}$ в соотношении сырье : экстрагент 1:30). Максимальное суммарное количественное извлечение данным способом составило $902,2 \pm 4,9$ мг $/ 100$ г.

2. Методом ВЭЖХ с использованием УФ-детектора определён антоциановый состав ягод рябины черноплодной, произрастающей на территории Красноярского края.

3. Выявлено, что качественный и количественный состав антоцианов ягод рябины черноплодной, произрастающей в разных районах Красноярского края, различается незначительно.

\section{Список литературы}

1. Куркин В.А. Фармакогнозия: учебник для студентов фармацевтических вузов (факультетов) 2-е изд., перераб. и доп. Самара: Офорт, 2007. С. 1176. [Kurkin V. A. Pharmacognosy: a textbook for students of pharmaceutical universities (faculties). 2nd ed., Rev. and add. Samara: « Ofort «, 2007. 1176 p. (In Russ.)]

2. Путырский И.Н., Прохоров В.Н. Универсальная энциклопедия лекарственных растений. М.: Махаон, 2000. 654 с. [Putyrskaya I. N., Prokhorov V. N. Universal Encyclopaedia of medicinal plants. Moscow: Mahaon, 2000. 654 p.(In Russ.)] 
3. Макаревич А.М., Шутова А.Г., Спиридович Е.В., Решетников В.Н. Функции и свойства антоцианов растительного сырья // Труды БГУ. 2010. Т. 4, вып. 2. С. 1-11. [Makarevich А. М., Shutova A .G., Spiridovich E.V., Reshetnikov V.N. Functions and properties of anthocyanins vegetable raw materials. Proceedings of the Belarusian State University. 2010. Vol .4(2). P. 1-11. (In Russ.)]

4. Stoner D.G., Wang. L. S., Zikri N., Chen T., Hecht S.S., Huang C. S., Sardo C., Frechner J. Cancer Prevention with Freeze-dried Berries and Berry Components // Semin Cancer Biol. 2007. 17(5). P. 403-410.

5. Левин Б.Д., Федюлин А.С. Возможные пути переработки плодов аронии черноплодной // Вестник КрасГАУ. 2006. №10. C. 315-318.[Levine B. D., Fedyulin A.S. Possible ways of processing fruits chokeberry Aronia.. VESTNIK of KSAU. 2006. №10. P. 315-318. (In Russ.)]

6. Rudakov O. B., Khairutdinova A. D., Odin A.P., Bolotov V. M. Fractional composition of anthocyan dyes from vegetative extractes and its control by the mrthod of HPLC // Proceedigs of Voronezh state University. Series of Chemistry. Biology. Pharmacy. 2004. №1. P. 85-93. (In Russ.)]

7. Логвинова Е. Е., Брежнева Т. А., Сливкин А. И., Самылина И.А., Берест И.С. Выбор оптимальных условий извлечения антоциановых соединений из высушенных и свежесобранных плодов рябины черноплодной // Вестник ВГУ. Серия Химия. Биология. Фармация. 2014. № 1. C. 122-125.[Logvinova E.E., Brezhnev T.A., Slivkin A.I.,. Samylina I. A., Berest I.S. Selection of optimum extraction conditions of anthocyanin compounds from dried fruits and freshly black chokeberry // Proceedigs of Voronezh state University. Series of Chemistry. Biology. Pharmacy. 2014. № 1. P. 122-125. (In Russ.)]

8. Ochmian I., Grajkowski J., Smolik M. Comparison of some morphological features, quality and chemical content of four cultivars of chokeberry fruits (Aronia melanocarpa) // Not Bot Horti Agrobo. 2012. 40(1). P. 253-260.

9. Jakobek L., Seruga M., Medvidovic-Kosanovic M., Novak I. Antioxidant activity and polyphenols of Aronia in Comparison to other Berry Species // Agriculturae Conspectus Scientificus. 2007. Vol. 72. No.4. P. $301-306$.

10. Viskelis P., Rubinskienè M., Bobinaitė R., Dambrauskienė E. Bioactive compounds and and antioxidant activity of small fruits in Lithuania // Journal of Food, Agriculture and Environment. 2010. Vol. 8. (3\&4). P. 259-263.

11. Skupień K., Oszmiański J. The effect of mineral fertilization on nutritive value and biological activity of chokeberry fruit // Agriculturaland food science. 2007. Vol. 16. P. 46-55.

12. Ochmian I., Oszmianski J., Skupien K., Chemical composition, phenolics, and firmness of small black fruits // Journal of Applied Botany and Food Quality. 2009. 83. P. 64-69.

13. ГОСТ Р 53956-2010 Фрукты быстрозамороженные. Общие технические условия. М.: Стандартинформ, 2011. 20 c.[GOST R 53956-2010. Fruit frozen. General specifications. Moscow: Standartinform, 2011. P. 20. (In Russ.)]

14. Овсянникова Е.А., Киселева Т.Ф., Потапов А.Н., Дюжев А.В. Исследования процесса экстрагирования дикорастущих ягод Сибири с использованием биокаталитических методов // Техника и технология пищеввых производств. 2012. № 4. С. 1-4. [Ovsyannikova E. A., Kiseleva T.F., Potapov A. N., Dyuzhev A.V. Study the extraction process wild berries Siberia using biocatalytic methods. Food Processing: Techniques and Technology. 2012. № 4. P. 1-4. (In Russ.)] 
15. Куркин В.А., Рязанова Т.К. Новые подходы к стандартизации плодов черники обыкновенной // Химия растительного сырья. 2012. №4. C. 167-173. [Kurkin V.A., Ryazanova T.K. New approaches to standardization of fresh fructus of vaccinium myrtillus L. // Chemistry of plant raw material. 2012 . №4. P. 167-173. (In Russ.)]

16. Переверткина И.В., Волков А.Д., Титова Н.Н., Болотов В.М. Оптимизация условий экстрагирования антоциановых красителей из растительного сырья // Химия растительного сырья. 2014. №2. C.137-141.[Perevertkina I.V., Volkov A. D., Titova N.N., Bolotov V.M. Optimization of conditions for antocyanin dyes extraction from the vegetable. Chemistry of plant raw material. 2014. №2. P. 167-173. (In Russ.)]]

17. Bräunlich M., Slimestad R., Wangensteen H., Brede C., Malterud K. E., Barsett H. Extracts, Anthocyanins and Procyanidins from Aronia melanocarpa as Radical Scavengers and Enzyme Inhibitors // Nutrients. 2013. 5(3). P. 663-678.

18. Nakajima J., Tanaka I., Seo S., Yamazaki M., Saito K. LC/PDA/ESI-MS Profiling and Radical Scavenging Activity of Anthocyanins in Various Berries // Journal of Biomedicine and Biotechnology. 2004. 5. P. 241-247. 